\title{
Pattern of Adverse Drug Reactions in a Govt. District Headquarters Hospital in Tamilnadu, India
}

\author{
Ponnusankar Sivasankaran*, Megha Gupta, Roopa Basutkar Satyanarayan, Raja Durai \\ Department of Pharmacy Practice, JSS College of Pharmacy, Ootacamund, JSS University, Mysore, INDIA.
}

\begin{abstract}
Background: Several literatures have reported adverse drug reaction between 5.9 to $22.3 \%$ among hospitalized patient in India and western countries respectively. The present study was undertaken to know the incidence of adverse drug reactions among the hospitalised patients at a secondary care hospital in South India. Method: One year and ten months prospective study included 1000 hospitalized patients at a secondary care hospital whose medical records were reviewed. Suspected adverse drug reactions were evaluated for causality, preventability and severity by Naranjo's probability scale, modified Schumock and Thornton's criteria, and modified Hartwig's criteria, respectively. Results: Among the 1000 hospitalized patients medical charts reviewed, 80 patients experienced adverse drug reaction. Type A reaction accounted for most of adverse drug reaction. $73.75 \%$ of the adverse drug reaction was preventable. $56.25 \%$ was found to be mild, $43.75 \%$ moderate and none of adverse drug reactions was severe. Among the adverse drug reaction $43.75 \%$ were reported with diuretic class of drug. The organ systems affected mostly were gastro intestinal tract $(46.25 \%)$ and haematological system (15\%). The significant association was found with age and incidence of adverse drug reaction in the study population. The occurrence of ADR was higher in male medical and lesser in paediatric units. Conclusion: In the present study fewer hospitalised patients experienced adverse drug reactions than compared to study reported by western countries.
\end{abstract}

Key words: Adverse drug reaction, Hospitalised patients, Pharmacovigilance, Medical units, Spontaneous reporting, South India.

\section{INTRODUCTION}

ADR detection relies on post marketing studies and spontaneous reporting, as the rare ADRs of the drugs go undetected in clinical trials. Spontaneous reporting suffers from limitations like under reporting, biased decision by the physician, lack of awareness and time. ${ }^{1}$ Around 84,470 Individual Case Safety Reports (ICRS) were reported under pharmacovigilance program of India till May $2014^{2}$ and 43, 161 is reported during the period of 1 June 2014 to 31 May 2015 in the VigiBase as mentioned Uppasala report 70 of July $2015 .^{3}$

In India, incidence of ADR is between 5.9 to $22.3 \%$ while deaths due to ADRs account for $1.8 \% .4,5$ The United States Food and Drug Administration (USFDA) and European Medical Agency (EMEA) emphasize the need to continually evaluate the beneficial and harmful effects of drugs in order to provide appropriate, safe and effective drug therapies. ${ }^{6,7}$

Adverse Drug Reactions (ADRs) are one of the major causes for decreased quality of life and mortality. Hospital admission due to ADRs varies from $2.9 \%$ to $5.6 \%$ and $35 \%$ of hospitalised patients experience ADRs. ${ }^{8}$ ADRs erode patient's confidence by increasing their length of hospital stay, affect quality of life and importantly imparts financial burden. Also they are the seventh leading cause of death. ${ }^{1}$ We evaluated the extent of ADRs occurred in hospitalized patients in this present study.

\section{MATERIALS AND METHODS}

The study population comprised of in-patients belonging to five units (Male Medical unit, Female Medical Unit, Intensive care unit,
Submitted date : $26 / 12 / 2015$

Accepted date : 13/01/2015

DOI: 10.5530/ijopp.9.1.7

Address for

correspondence:

Dr. Ponnusankar

Sivasankaran,

Department of Pharmacy

Practice,

JSS College of Pharmacy,

Ootacamund (Ooty)-643 001.

Nilgiris, INDIA.

Phone no: +91-9489613428

E-mail: ponnusankarsivas@ gmail.com 
Paediatric unit and Surgical unit) of 420 bedded secondary care hospital located in Ootacamund (Ooty), the Nilgiris district, Tamilnadu, India. The patients were assessed by comprehensive collection of ADR data by a single trained pharmacist over a period of one year and ten months from September 2013 to July 2014. The study was approved by Institutional Review Board, JSS College of Pharmacy, Ootacamund, JSSCP/DPP/ IRB/003/2013-14).

The patients admitted due to drug abuse, intentional and accidental poisoning, over dose of medications, with medication error or non-compliance and patients who were hospitalised on Sunday and discharged on the same day were excluded from the study.

Study wards were visited by the researcher, all the patients' medications order and nursing notes were screened for the presence of ADRs as per the guidelines by World Health Organisation (WHO). ${ }^{9}$ Objective markers like laboratory results and subjective markers of ADRs like diarrhoea, vomiting and rash are identified through patient's records. The outcome of the patients is assessed by daily review of the medical records.

Discussion with the physician of the wards and wherever appropriate discussion with patients was done. All health care team members were informed about the study, to notify any such ADR in person or over phone or through the notification card available in the wards. The Naranjo's scale was used to assess the degree of classification of ADRs. ${ }^{10}$ The Schumock and Thornton criteria and Hartwig scale were used to assess the preventability and severity of the reaction. ${ }^{11,12}$ The WHO Anatomical Therapeutic and Chemical classification and WHO-Adverse Reaction Terminologies (WHO-ART) are used to code for the drugs prescribed and ADRs experienced by the hospitalised patients respectively.

\section{Statistical Analysis}

The data obtained was analysed using GraphPad Prism version 6.04 for Windows and SPSS version 22.0 for windows (SPSS Inc., Chicago II, USA). Descriptive listing was performed for characteristics of ADRs. Results are expressed as percentage, mean $( \pm \mathrm{SD})$ for numerical variables. The total incidence of in-patients ADRs was defined as total number of inpatients who developed ADR during the study period in relation to total number of in-patients in the study wards. $\chi^{2}$ square and student ' $\mathrm{t}$ '-test were applied wherever appropriate and P-value of less than 0.05 was considered significant.

\section{RESULTS}

A total of 1000 patient's medication charts were reviewed during the period of one year and ten months. Among them, $80(8 \%)$ had one or more ADRs, $77(96.25 \%)$ wereidentified by the trained pharmacists and remaining $3(3.75 \%)$ was detected by physician. Table 1 mentions the list of demographic details with age wise distribution with incidence of ADRs reported and without any incidence of ADRs. Out of 1000 patient's medical chart reviewed, the patients aged above 60 years had higher incidence of ADRs (14.91\%) when compared with other age groups. There was significant association between patients age and ADRs occurrence $(\mathrm{P}>0.05)$. The mean age of the study population who reported ADR was 52.21 years. The ADR incidence was higher in female patients $(9.2 \%)$ than male however gender was not associated to ADR $(\mathrm{P}=0.3217)$.

The odds ratio of ADRs among the hospitalized patients in the respective medical units were analysed (Table 2). It was found that the patients admitted to male medical ward experienced higher ADR than any other ward with Intensive care unit being the reference $(\mathrm{P}=0.0237)$. The incidence of ADR was 2.13 times higher in male medical unit in comparison to Intensive care unit.

The drug class diuretics is associated with higher incidence of ADRs, 43.75\% ( $\mathrm{n}=35)$. Among diuretics, furosemide was found to cause more ADRs (31\%); and diarrhoea being mostly reported (Table 3 ). The organ system that was affected was gastro intestinal tract $37(46.25 \%)$ followed by haematological system $12(15 \%)$ as mentioned in Table 4.

Among the reported ADRs, $56.25 \%$ was found to be mild, $43.75 \%$ moderate and none of ADRs was severe in nature. $78.75 \%$ was probable and, $21.25 \%$ was possible and none of the patients had definite and unlikely. $93.75 \%$ of the patient experienced type A reactions and the rest had type $\mathrm{B}$ reactions as per the Wills and Brown classification for the adverse drug reactions (Table 5). In the present study, $78.75 \%$ of adverse drug reactions were recovered/resolved with sequelae, $12.5 \%$ were recovering/resolving and only $8.75 \%$ of cases were recovered/resolved from ADRs. As per the Thornton preventability scale it was found that $73.75 \%$ were preventable followed by $25 \%$ were not preventable and $1.25 \%$ definitely preventable in the study. Overall, there was $90 \%$ agreement between the assessors in the causality, preventability, and severity assessments.

\section{DISCUSSION}

The adverse drug reactions related problems with the drug are a concern, when administered at the therapeutic level and cause harm in various ways. Globally the incidences of adverse events were around 43 million 


\begin{tabular}{ccc} 
Table 1: Demographic characteristics of the patients \\
Characteristics & $\begin{array}{c}\text { No. of patients with } \\
\text { ADR (\%) }\end{array}$ & $\begin{array}{c}\text { No. of patients without } \\
\text { ADR (\%) }\end{array}$ \\
\hline \multicolumn{3}{c}{ Age (Years) } \\
18 & $3(1.68)$ & $175(98.31)$ \\
$18-60$ & $40(6.96)$ & $534(93.03)$ \\
$>60$ & $37(14.91)$ & $211(85.05)$ \\
& & \\
Gender & $\left(\chi^{2=} 26.61, \mathrm{df}=2, P<0.0001\right)$. \\
Male & $50(7.41)$ & $625(92.59)$ \\
Female & $30(9.2)$ & $295(90.77)$ \\
& $\left(\chi^{2=}\right.$ & $0.991, \mathrm{df}=1, P=0.319$ \\
\end{tabular}

Table 2: Adverse drug reactions reported in different units

\begin{tabular}{cccc} 
Unit type & No. of ADRs & Odds ratio & P value \\
\hline Intensive care unit & Ref & -- & -- \\
Male medical unit & 38 & $2.139(1.109-4.126)$ & 0.023 \\
Female medical unit & 25 & $1.716(0.853-3.450)$ & 0.172 \\
Paediatric unit & 02 & $0.1670(0.0371-0.750)$ & 0.008 \\
Surgical unit & 02 & $0.3767(0.0830-1.709)$ & 0.247 \\
\hline
\end{tabular}

\section{Table 3: Drugs mostly found to cause ADR among the study population}

\begin{tabular}{|c|c|c|c|}
\hline Drug Class & $\begin{array}{l}\text { Number (\%) } \\
\text { ADRs }\end{array}$ & Drugs Name & ADRs (Number) \\
\hline Anti -ulcers & $7(8.75)$ & T. Ranitidine (7) & $\begin{array}{l}\text { Granulocytosis (6), } \\
\text { Metabolic Acidosis (1) }\end{array}$ \\
\hline Antibiotics & $14(17.5)$ & $\begin{array}{l}\text { C. Doxycycline (1) } \\
\text { Inj. Gentamycin (10) } \\
\text { T. Ciprofloxacin (2) } \\
\text { T. Cefotaxim (1) }\end{array}$ & $\begin{array}{l}\text { Pain (1), Dehydration (8), } \\
\text { Diarrhea (4), Hypertension (1) }\end{array}$ \\
\hline Cardio glycoside & $1(1.25)$ & T. Digoxin (1) & Tonsillitis (1) \\
\hline Anti-coagulants & $2(2.5)$ & $\begin{array}{l}\text { T. Warfarin } 7(1) \\
\text { Inj. Heparin (1) }\end{array}$ & $\begin{array}{c}\text { Chronic Heart Failure (1), } \\
\text { Oliguria (1) }\end{array}$ \\
\hline \multirow[t]{4}{*}{ Diuretics } & \multirow[t]{4}{*}{$35(43.75)$} & T. Furosemide (35) & $\begin{array}{c}\text { Hypothermia (1), Diarrhea (15), Myocardial Infraction (1), } \\
\text { Dehydration (8), Anemia (3), } \\
\text { Diabetic ketoacidosis (3), } \\
\text { Pharyngitis (1), Diabetes mellitus (2) }\end{array}$ \\
\hline & & T. Spironolactone (3) & Hemolytic Anemia (1), Oliguria (1), Acidosis (1) \\
\hline & & Inj. Mannitol (1) & Acidosis (1) \\
\hline & & T. Aspirin $150 \mathrm{mg}(2)$ & $\begin{array}{l}\text { Myocardial Infarction(1), } \\
\text { Chronic Heart Failure(1) }\end{array}$ \\
\hline \multirow[t]{2}{*}{ NSAIDs } & \multirow[t]{2}{*}{$6(7.5)$} & T. Ibuprofen (3) & Acute Renal Failure (1), Vomiting (1), Dehydration (1) \\
\hline & & T. Paracetamol (1) & Dehydration (1) \\
\hline Anti-retroviral & $4(5)$ & T. Zidovudine (4) & Anemia (4) \\
\hline Steroids & $4(5)$ & Inj. Hydrocortisone (4) & Jaundice (4) \\
\hline Antihypertensive & $5(6.25)$ & $\begin{array}{l}\text { T. Atenolol (3) } \\
\text { T. Enalapril (2) }\end{array}$ & $\begin{array}{c}\text { Myocardial Infarction (1), Hypothyroidism (2) } \\
\text { Dehydration (2) }\end{array}$ \\
\hline Bronchodilators & $1(1.25)$ & T. Deriphylline (1) & Myocardial Infarction (1) \\
\hline Psychotropic drugs & $1(1.25)$ & Inj. Diazepam & Mononucleoside syndrome (1) \\
\hline
\end{tabular}




\begin{tabular}{cc}
\hline Table 4: Organ system implicated by ADRs \\
Organ System Affected & $\begin{array}{c}\text { No. of ADRs (\%) } \\
\text { (n=80) }\end{array}$ \\
\hline Respiratory & $2(2.50)$ \\
Muscoskeletal & $1(1.25)$ \\
Gastro intestinal & $37(46.25)$ \\
Genitourinary & $6(7.50)$ \\
Cardio vascular & $2(2.50)$ \\
Neurological & $5(6.25)$ \\
Hematological & $12(15)$ \\
Endocrine & $8(10)$ \\
Urinary & $2(2.50)$ \\
Nephrological & $1(1.25)$ \\
Hepatic & $4(3.75)$ \\
Sensory & $2(2.50)$ \\
\hline
\end{tabular}

each year and caused disability among 23 million. Among this two third occur in low income and middle income countries. ${ }^{1}$ The present study was undertaken to know the prevalence and asses the causality and preventability at the secondary care hospital. The prevalence of ADRs among the hospitalized patients in the study were $8 \%$ which was lower when compared with other studies conducted elsewhere. ${ }^{13,14}$ The majority of the hospitalized patients experienced ADRs were in the age group of greater than 60 years $(14.91 \%)$ followed by $18-60$ years $(6.96 \%)$ and this finding are similar from the other study conducted in India. ${ }^{15}$ But when compared with the study by Scheneider JK et al. ${ }^{16}$ the incidence of ADRs found in the elderly population in our study was less. The possible reason might that the disease pattern experienced in this population is different and the variation in the way the study was conducted among the hospitalised patients in the different units. In our study, ADRs commonly occurs in women when compared to men the finding is similar when compared with other studies; as the CYP P450 (CYP 3A4) activity is higher in females than compared with males as this enzyme will cause different effects on the drug metabolism, though the physician don't change the dosage of the drug based on the gender but it is important to consider while prescribing the narrow therapeutic range drugs. Female are more likely than men to interpret the discomfort that is caused. ${ }^{17-20}$ In this study, 96.25\% $(\mathrm{n}=77)$ of ADR was identified and reported by trained pharmacist and $3.75 \%(\mathrm{~N}=3)$ by the physician respectively, thus the advantage of the trained pharmacist in identifying ADR is due to their ward round participation, patient interview and careful monitoring of laboratory data of patients. Most of the patients experienced diarrhoea affecting the gastro-intestinal organ system which is also similar to the study by Suh DC et al. ${ }^{21}$ Murphy et al. ${ }^{8}$ and Biradar et al..$^{22}$ reported that aminogly-
Table 5: Level of severity and type of reaction

\begin{tabular}{cccc}
$\begin{array}{c}\text { Level of } \\
\text { severity }\end{array}$ & No of ADRs (\%) & Type & No of ADR (\%) \\
\hline Mild & $45(56.25)$ & Probable & $63(78.75)$ \\
Moderate & $35(43.75$ & Possible & $17(21.25)$ \\
Severe & - & Definite & - \\
Total & 80 & Unlikely & - \\
\hline
\end{tabular}

coside and non-opioid analgesics were the most offending drugs. Based on the ATC classification the drug furosemide was the mostly implicated drug resulted in ADRs in the present study. Furosemide causing diarrhoea, the reason is unknown. In the present study it is found that the incidence of ADR was higher in male medical unit compared to other units, this finding is similar to study reported by Davies et al. ${ }^{23}$

In the present study, we did not find the association with the number of drugs that was administered to the patients as the ADRs that were found was associated with the individual drug prescribed by the physician. Thus, emphasising the need for strong monitoring the medical records by the clinical pharmacists of hospitalised patients receiving medication. Among the geriatrics population on who experience multiple disease conditions and are associated with high risk of ADRs due to drug-drug interactions. Our study found that $100 \%$ of ADRs were either possible or probable of which $73.75 \%$, preventable which is similar to other research findings. ${ }^{24,25}$ Most type of ADRs reported in the study is of Type A reactions as reported by other researchers. ${ }^{26,27}$ Unlike most studies, the hospital admissions due to ADRs are preventable. The ADRs reported in the study are mostly mild in nature self-limiting which resolves over a period of time which shows the drug used in the management of different medical conditions is properly managed by the treating physician who uses only the drugs listed under essential drug list of Government of Tamilnadu. Thus, this controlled use of drugs has contributed to improved understanding and better therapeutic management of medical conditions at the secondary care hospital set-up.

The advantage of the present study is that it is prospective in nature allowing capture more accurate recording of both the drug history and symptoms, and the assessment of causality. The limitation of the study was that the drug usage pattern before admission was not obtained by the patients as they were unable to provide the information and also recall bias is highly possible.

\section{CONCLUSION}

In this study, 8 per cent of the hospitalised patients experienced adverse drug reactions. Though this is 
fewer compared to western countries, the spontaneous reporting of ADR by the physician is lacking, indicating the need to create awareness of ADR reporting. Wellstructured pharmacy and therapeutic committee and its functioning will further strengthen the ADR monitoring program of India.

Authors' contribution: All four authors (PS, MG, RSB and RD) have significantly contributed to this study with respect to research idea; design of the study; collection, analyses, and interpretation of data; and writing and/or revising the submitted manuscript adhering to ICMJE definition of authorship.

\section{ACKNOWLEDGEMENT}

The authors wish to thank JSS University, Mysore and Govt. District Headquarters Hospital (GHQH), Ootacamund for providing the necessary facilities to conduct this work.

Funding: The authors would like to thank Tamilnadu Pharmaceutical Sciences Welfare Trust (PIC Trust), Chennai, India for providing financial support through student research project grant (TNPSWT: 2013/2163) to Ms. Megha Gupta for this work.

\section{CONFLICT OF INTEREST}

The authors declare that they have no competing interests to disclose.

\section{ABBREVIATIONS USED}

$\begin{array}{ll}\text { ICSR: } & \text { Individual Case Safety Report } \\ \text { ADR: } & \text { Adverse drug reaction }\end{array}$

\section{REFERENCES}

1. Janet S, Paola C, Gianluca T. Clinical and economic burden of adverse drug reactions. J Pharmacol Pharmacother. 2003;4(1):S73-S7.

2. http://www.ipc.gov.in/PvPI/Current $\% 20$ Status $\% 20$ of $\% 20$ NCC $\% 20$ till\%20 31 $\% 20$ May\%202014.pdf. [Retrieved on August 2014].

3. Lindquist, Uppsala Monitoring Centre Reports, July 2015.

4. Jha K, Larizgoitia I, Audera-Lopez C, Prasopa-Plaizier N, Waters H, Bates DW. The global burden of unsafe medical care: analytic modelling of observational studies. BMJ Qual Saf. 2013;22(10):809-15.
5. Amrita P, Singh SP. Status of spontaneous reporting of adverse drug reaction by physicians in Delhi. J Pharm Pract. 2011;4(2):29-36.

6. Pearson KC, Kennedy DL. Adverse drug reactions and the Food and Drug Administration. J Pharm Pract. 1989;2(4):209-13.

7. Ema. Directive (EU) 2010/84. Off. J. Eur. Union, L Ser. 2010;74-99.

8. Murphy, BM., Frigo, LC. Development, implementation and results of a successful multidisciplinary adverse drug reactions reporting program in a university teaching hospital. Hosp Pharm. 1993;28(12):1199-204.

9. Edwards IR, Aronson JK. Adverse drug reactions : definitions, diagnosis, and management. Lancet. 2000;356(9237):1255-9.

10. Naranjo CA, Busto U, Sellers EM, Sandor P, Ruiz I, Roberts EA, et al. A method for estimating the probability of adverse drug reactions. Clin Pharmacol Ther. 1981;30(2):239-45.

11. Schumock GT, Thornton JP. Focusing on the preventability of adverse drug reactions. Hosp Pharm. 1992;27(6):538.

12. Hartwig SC, Siegel J, Schneider PJ. Preventability and severity assessment in reporting adverse drug reactions. Am J Hosp Pharm. 1992;49(9):2229-32.

13. Claven DC, Pestornik SL, Evans RS, Lloyd JE, Duke JP. Adverse drug events in hospitalized patients. JAMA. 1997; 277(4):301-6.

14. Ramesh M, Pandit J, Parthasarathi G. Adverse drug reactions in a south Indian hospital-their severity and cost involved. Pharmacoepidemiol Drug Saf. 2003;12(8):687-92.

15. D'Cruz MS, Sachdev A, Tiwari P. Adverse drug reactions and their risk factors among Indian ambulatory elderly patients. Indian J Med Res 2012;136(3): 404-10.

16. Scheneider JK, Mion LC, Frengley JD. Adverse drug reactions in an elderly outpatient population. Am J Hosp Pharm. 1992;49(1):90-6.

17. Lemmens HJM, Burm AGL, Hennis PJ. Influence of age on the pharmocokinetic of Alfentanil. Clin Pharmcokinetic. 1990:19(5):416-22.

18. Harris RZ, Benet LZ, Schwartz JB. Gender effects in pharmacokinetics and pharmacodynamics. Drugs. 1995;50(2):222-39.

19. Wilkinson GR. Cytochrome P4503A(CYP3A) metabolism:predicition of in vivo activity in humans. J Pharmacokin Bio Pharm. 1996;24(5):475-90.

20. Alomar MJ. Factors affecting the development of adverse drug reactions. Saudi Pharm J. 2014;22(2):83-94.

21. Suh DC, Woodall BS, Shin SK, Hermes-De-Santis ER. Clinical and economic impact of adverse drug reactions in hospitalised patients. Ann Pharmacother. 2000;34(12):1373-9

22. Biradar V, Urmila A, Renuka S, Pais P. Clinical spectrum of hospital acquired renal failure: A study from tertiary care hospital. Indian J Nephrol. 2004;14:93-6.

23. Davies EC, Green CF, Taylor S, Williamson PR, Mottram DR, Pirmohamed M. Adverse drug reactions in hospital in-patients: A prospective analysis of 3695 patient-episodes. PLoS One. 2009;4(2),e4439.

24. Bates DW, Cullen DJ, Laird N, Petersen LA, Small SD, Servi D. Incidence of adverse drug events and potential adverse drug events: implications for prevention. ADE Prevention Study Group. JAMA. 1995;274(1):29-34.

25. Ducharme MM, Boothby LA. Analysis of adverse drug reactions for preventability. Int J Clin Pract. 2007;61(1):157-61.

26. Moore N, Lecointre D, Noblet C, Mabille M. Frequency and cost of serious adverse drug reactions in a department of general medicine. $\mathrm{Br} \mathrm{J}$ Clin Pharmacol. 1998;45(3):301-308.

27. Camargo AL, Cardoso FMB, Heineck I. Adverse drug reactions: a cohort study in internal medicine units at a university hospital. Eur J Clin Pharmacol. 2006;62(2):143-9. 